\title{
Effects of methamphetamine abuse and serotonin transporter gene variants on aggression and emotion-processing neurocircuitry
}

\author{
DE Payer ${ }^{1}$, EL Nurmi ${ }^{1}$, SA Wilson ${ }^{1}$, JT McCracken ${ }^{1}$ and ED London ${ }^{1,2,3}$
}

Individuals who abuse methamphetamine (MA) exhibit heightened aggression, but the neurobiological underpinnings are poorly understood. As variability in the serotonin transporter (SERT) gene can influence aggression, this study assessed possible contributions of this gene to MA-related aggression. In all, 53 MA-dependent and 47 control participants provided self-reports of aggression, and underwent functional magnetic resonance imaging while viewing pictures of faces. Participants were genotyped at two functional polymorphic loci in the SERT gene: the SERT-linked polymorphic region (SERT-LPR) and the intron 2 variable number tandem repeat polymorphism (STin2 VNTR); participants were then classified as having high or low risk for aggression according to individual SERT risk allele combinations. Comparison of SERT risk allele loads between groups showed no difference between MA-dependent and control participants. Comparison of self-report scores showed greater aggression in MAdependent than control participants, and in high genetic risk than low-risk participants. Signal change in the amygdala was lower in high genetic risk than low-risk participants, but showed no main effect of MA abuse; however, signal change correlated negatively with MA use measures. Whole-brain differences in activation were observed between MA-dependent and control groups in the occipital and prefrontal cortex, and between genetic high- and low-risk groups in the occipital, fusiform, supramarginal and prefrontal cortex, with effects overlapping in a small region in the right ventrolateral prefrontal cortex. The findings suggest that the investigated SERT risk allele loads are comparable between MA-dependent and healthy individuals, and that MA and genetic risk influence aggression independently, with minimal overlap in associated neural substrates.

Translational Psychiatry (2012) 2, e80; doi:10.1038/tp.2011.73; published online 21 February 2012

\section{Introduction}

Methamphetamine (MA) abuse is associated with a high incidence of interpersonal violence, ${ }^{1}$ confirmed by consistent reports of heightened hostility and aggression scores in MAabusing research participants. ${ }^{2-8}$ Aggressive behavior can stem from abnormalities in neurocircuitry underlying emotion processing, including serotonergic disturbances, ${ }^{9}$ and dysfunction of the amygdala (which is involved in the detection of emotional salience in environmental stimuli) and prefrontal cortex (PFC, which takes part in deliberative and executive functions). ${ }^{10-12}$ MA-abusing individuals indeed show PFC and amygdala abnormalities, ${ }^{13,14}$ as well as differences in serotonergic markers, ${ }^{5,15}$ relating to socio-emotional disturbances such as poor social cognition, insight, and harm avoidance, ${ }^{8,16-20}$ low mood $^{21}$ and hostility/aggression itself. ${ }^{5,6,8}$ In addition to creating personal and public health and safety concerns, ${ }^{22}$ these mood states and behaviors can negatively impact treatment outcome, as emotional distress can contribute to drug craving and relapse. ${ }^{23}$ Given the relevance to abstinence success, therefore, it is important that the etiology of these neurochemical and social-cognitive factors be clarified.

MA is considered a potent neurotoxin, ${ }^{24}$ and in animal models, repeated administration results in the degeneration of monoamine nerve terminals; ${ }^{25}$ it is therefore possible that the observed neurocognitive deficits reflect neuronal damage and/or compensatory changes following long-term MA abuse. However, independently of MA abuse, the same neural circuits and behaviors are also influenced by normal genetic variability in the serotonin system, ${ }^{26-28}$ raising the possibility that the observed differences predate MA abuse. As each possibility may favor different treatment approaches, this study investigated the contribution of genetic factors, in addition to MA abuse, to aggression and brain function.

One integral gene to variability in the serotonin system is SLC6A4, which encodes the serotonin transporter (SERT) protein and contains two well-studied functional polymorphisms. The first, the SERT-linked polymorphic region (SERT-LPR), is located within the gene promoter and consists of the insertion/deletion of a 44-base-pair repetitive element, resulting in a short or long allele. An additional single-nucleotide polymorphism mapping within the LPR (rs25531) modifies the effect of the long allele, with the minor $(\mathrm{g})$ allele rendering it functionally similar to the short allele. ${ }^{29}$ The short allele has reduced transcriptional efficiency and lower expression levels, ${ }^{30}$ and is associated with phenotypes related to negative emotionality, including aggression and violence, ${ }^{31-35}$ mood disorders and anxiety, ${ }^{36-38}$ altered socio-emotional function

${ }^{1}$ Department of Psychiatry and Biobehavioral Sciences, University of California, Los Angeles, CA, USA; ${ }^{2}$ Department of Molecular and Medical Pharmacology, University of California, Los Angeles, CA, USA and ${ }^{3}$ Brain Research Institute, University of California, Los Angeles, CA, USA

Correspondence: Dr ED London, UCLA Semel Institute for Neuroscience and Human Behavior, 740 Westwood Plaza, Room C8-831, Los Angeles, CA 90095, USA. E-mail: elondon @mednet.ucla.edu

Keywords: aggression; amygdala; methamphetamine; prefrontal cortex; SERT-LPR; STin2 VNTR

Received 8 December 2011; accepted 11 December 2011 
and social sensitivity ${ }^{39-41}$ and differences in amygdala and PFC structure and function. ${ }^{42-44}$

The second polymorphism, a variable number tandem repeat in intron 2 of the SERT gene (STin2), resulting in 9, 10 or 12 repeats of a 17-base-pair sequence, can also affect gene expression. The 12-repeat allele (particularly the 12/12 genotype) has been linked to aggression, ${ }^{45,46}$ mood and anxiety disorders ${ }^{47-49}$ and impulsivity and disinhibition. ${ }^{50,51}$ The two polymorphisms therefore influence social-cognitive and emotional processes that can result in heightened aggression. Importantly, the two polymorphic domains interact, suggesting that they should be studied in combination rather than independently. ${ }^{51-53}$

As MA- and SERT-related effects resemble one another, it is possible that differences previously attributed to MA abuse in fact reflect differential risk allele loads or genotype effects between MA-abusing and healthy participants. In this regard, one study reported a higher SERT-LPR short allele load in individuals with MA psychosis and spontaneous relapse to MA abuse, ${ }^{54}$ but another found no difference in SERT-LPR allele distribution between groups. ${ }^{55}$ Given these inconsistencies and limited outcome measures, this study sought to investigate the extent to which heightened aggression and differences in brain function reflect MA abuse status, genetic factors or a combination of both. Specifically, the study aimed (1) to determine whether heightened aggression in MAabusing populations reflects a higher SERT risk allele load, and (2) to test for effects of genetic risk and MA abuse status on self-reported aggression and brain activation.

\section{Materials and methods}

Participants and study procedure. All procedures were approved by the UCLA Office of the Human Research Protection Program. Non-treatment-seeking MA-dependent and healthy control volunteers between the ages of 18 and 55 years gave written informed consent, and were screened for eligibility using questionnaires, psychiatric diagnostic interviewing (SCID-IV ${ }^{56}$ ) and a medical examination. Participants in the MA group were required to meet the DSM-IV criteria for current MA dependence, and to demonstrate recent MA use by providing a urine sample that tested positive for MA. Control participants were required to have no history of drug abuse or dependence. Exclusion criteria for all participants were: any current Axis I diagnosis, except MA dependence or substance-induced mood/anxiety disorder (MA group) or nicotine dependence (both groups); use of psychotropic medications or substances, except some marijuana or alcohol (not meeting abuse or dependence criteria); and nervous system, cardiovascular, pulmonary or systemic disease.

Eligible MA participants were admitted to the UCLA General Clinical Research Center, and participated on a residential basis in a study lasting 15-30 days. They were required to abstain from all illicit drugs and alcohol for the duration of the study, verified by urine screening and breathalyzer. Eligible control participants visited the laboratory only on test days, and were required to test negative for illicit substances/alcohol on each test day. Study compensation was provided in cash and gift certificates. A total of 100 individuals (53 MA, 47 control) participated in the study (Table 1), and completed one or more (but not necessarily all) of the measures below.

Outcome measures. To assess aggressive behavior, participants completed a paper-and-pencil Aggression Questionnaire (AQ), ${ }^{57}$ indicating on a Likert scale (1-5) how well each of 34 items reflected their behavior.

Brain function was assessed using functional magnetic resonance imaging during observation of faces, as viewing faces reliably engages the amygdala and PFC. ${ }^{58}$ Presentation of face stimuli occurred in 25-s blocks, showing five distinct faces ${ }^{59}$ for $5 \mathrm{~s}$ each. Participants viewed a total of eight blocks (half showing neutral, and half angry/fearful facial expressions), each followed by $16 \mathrm{~s}$ of fixation.

MA use and withdrawal measures. MA participants reported MA use patterns (amount and frequency) during intake. Each day following intake, they completed a 30-item rater-scored Methamphetamine Withdrawal Questionnaire (MAWQ), ${ }^{60}$ assessing emotional, physical and functional withdrawal symptoms on a 4-point scale, and a Visual Analog Scale for Craving (VAS), indicating current levels of MA craving on a line marked from 0 to 100 in 10-point increments. For missing measures, scores from the preceding or following day (or their mean if both were available) were used to estimate scores.

Genotyping methods and analyses. Genotypes for the SLC6A4 SERT-LPR short/long variant, STin2 and rs25531 were assessed simultaneously according to the protocol published in ref. 29. Polymerase chain reaction products were electrophoresed in 3.5\% gold agarose (BMA, Rockland, ME, USA) gels in $1 \times$ Tris/Borate/EDTA and imaged with ethidium bromide under a fluorescent Kodak digital camera. Alleles were determined by comparison with molecular weight standards and data from control individuals with previously determined genotypes. All genotypes were confirmed in duplicate and samples were double-scored by two technicians independent of phenotype information. All assays included positive and negative control samples. All markers were in Hardy-Weinberg equilibrium.

Since complex phenotypes are more accurately predicted by multiple than single polymorphisms, we combined SERTLPR and STin2 genotypes according to Aluja et al., ${ }^{51}$ which predicts that carrying the LPR short (s) allele and homozygosity for the STin2 12-repeat allele should be risk factors for aggression. It is important to note that while our investigation focused on aggression, these risk factors are not specific, and may predispose to aggressive behavior indirectly. To categorize participants, we first calculated a 'number of risk factors' variable. Possible values were: 0 (LPR I/l + STin2 10+), 1 (LPR I/I + STin2 12/12 or LPR s/l (or I(g)/l) + STin2 $10+$ ), 2 (LPR s/l (or I(g)/l) + STin2 12/12 or LPR s/s (or $\mathrm{l}(\mathrm{g}) / \mathrm{s})+$ STin2 $10+$ ) and $3($ LPR s/s $($ or $\mathrm{l}(\mathrm{g}) / \mathrm{s})+$ STin2 12/12). Since the STin2 9-repeat allele is functionally unique and its effects are unclear, ${ }^{61}$ the three MA participants who were carriers were excluded. Given the small samples created by this division, participants were then grouped into genetic low-risk (0 or 1 risk factor) and high-risk (2 or 3 risk factors) groups. Independent analyses of the individual 


\begin{tabular}{|c|c|c|c|}
\hline & $\operatorname{MA}(\mathbf{N}=53)$ & Control $(\mathrm{N}=47)$ & Test for group difference \\
\hline \multicolumn{4}{|l|}{ Demographic measures } \\
\hline Number of men/women & $31 / 22$ & $25 / 22$ & \multirow{3}{*}{$\begin{array}{c}\chi^{2}(1)<1 \\
t(98)=1.19 \\
t(98)=5.80^{*}\end{array}$} \\
\hline Years of age (M, s.d.) & $34.4(9.4)$ & $32.1(9.5)$ & \\
\hline Years of education (M, s.d.) & $12.7(1.5)$ & $14.9(2.2)$ & \\
\hline \multicolumn{4}{|l|}{ Ethnicity (number of participants) } \\
\hline Caucasian & 29 & 28 & \multirow{7}{*}{$\chi^{2}(6)=10.65$} \\
\hline African American & 2 & 6 & \\
\hline Hispanic/Latino & 15 & 5 & \\
\hline Asian American & 2 & 5 & \\
\hline Native American & 0 & 1 & \\
\hline Multiple & 1 & 0 & \\
\hline Other & 4 & 2 & \\
\hline \multicolumn{4}{|l|}{ SERT-LPR genotype (number of participants) } \\
\hline Short/short & 14 & 11 & \multirow{3}{*}{$\chi^{2}(2)<1$} \\
\hline Short/long & 22 & 20 & \\
\hline Long/long & 17 & 16 & \\
\hline \multicolumn{4}{|l|}{ SERT-VNTR Genotype (number of participants) } \\
\hline 9/9 & 0 & 0 & \multirow{6}{*}{$\chi^{2}(4)=3.25$} \\
\hline $9 / 10$ & 1 & 0 & \\
\hline $9 / 12$ & 2 & 0 & \\
\hline $10 / 10$ & 9 & 6 & \\
\hline $10 / 12$ & 18 & 18 & \\
\hline $12 / 12$ & 23 & 23 & \\
\hline \multicolumn{4}{|l|}{ MA use measures ( $M$, s.d.) } \\
\hline Years of MA use & $11.0(7.7)$ & \multirow{4}{*}{ NA } & \multirow{4}{*}{ NA } \\
\hline Years of heavy MA use $(3 \times$ per week or 2 -day binges) & $7.82(7.0)$ & & \\
\hline Days MA used per month & $20.8(9.1)$ & & \\
\hline Grams of MA used per week & $3.31(4.29)$ & & \\
\hline
\end{tabular}

Abbreviations: MA, methamphetamine; NA, not applicable; SERT-LPR, serotonin transporter-linked polymorphic region; SERT-VNTR, SERT-variable number tandem repeat polymorphism.

${ }^{\star} P<0.05$.

polymorphisms demonstrated consistent but less robust effects than when combined into risk groups (see Supplementary Materials).

\section{Imaging methods and analyses}

Apparatus and parameters. Imaging was performed on a 3T Siemens Allegra scanner (Erlangen, Germany), using a standard T2*-weighted gradient-echo echo-planar imaging pulse sequence to collect blood-oxygen-level-dependent signal. Acquisition parameters were: $\mathrm{TR}=2500 \mathrm{~ms}, \mathrm{TE}=28 \mathrm{~ms}$; flip angle $=80^{\circ}$; matrix $=64 \times 64$. Each volume consisted of 36 interleaved slices, parallel to the AC-PC line, with $2.5-\mathrm{mm}$ thickness and $0.5-\mathrm{mm}$ distance. Each of two functional runs yielded 210 volumes. T2-weighted and high-resolution T1weighted structural scans were also acquired for region-ofinterest (ROI) delineation and spatial normalization. Stimulus displays were generated using the MacStim software (WhiteAnt Occasional Publishing, West Melbourne, VIC, Australia) and presented through video goggles (Resonance Technology, Northridge, CA, USA).

Analysis. Data were processed using SPM5 (Wellcome Trust Centre for Neuroimaging, London, UK). Functional images were spatially realigned to the mean image to correct for head motion (within $3 \mathrm{~mm}$ translation $/ 5^{\circ}$ rotation; exceeding these parameters was exclusionary), and co-registered to individual structural templates. Amygdala ROls were drawn on high-resolution structural images using FSL FIRST. ${ }^{62}$ Functional scans were smoothed with a 5-mm Gaussian kernel, and masked with these ROls. Using the MarsBaR toolbox, ${ }^{63}$ a general linear model was applied at each voxel within the ROIs, containing regressors for neutral and emotional face blocks (modeled as boxcar functions convolved with the hemodynamic response function provided by SPM5) and fixation as an implicit baseline. After fitting the general linear model, percent signal change during observation of faces was calculated, and the resulting values exported to SPSS 16.0 (SPSS Inc., Chicago, IL, USA).

For whole-brain analyses, functional images were smoothed with an 8-mm Gaussian kernel, and the general linear model described above applied at each voxel across the brain. The resulting maps of parameter estimates were spatially normalized to a standard template provided by SPM5, and passed to a group-level random-effects analysis with MA abuse status (MA-dependent or control) and genetic risk (high or low) as factors. Results were assessed at a statistical threshold of $P<0.005$ with a cluster criterion of 30 contiguous voxels, offering a good balance between potential for Type I and Type II errors. ${ }^{64}$

\section{Results}

Demographic, genotype and MA use measures. MA and control groups were matched for age, sex and ethnicity, but 
MA participants had completed fewer years of education (Table 1). Participants in the low and high genetic risk groups were matched for sex and education, but the low-risk group was marginally older $(t(95)=1.74, P=0.086)$, and groups were not matched for ethnicity $\left(\chi^{2}(6)=12.81, P=0.046\right)$. Demographic measures were therefore used to follow-up all analyses.

MA withdrawal measures. MA craving and physical withdrawal decreased significantly between intake and test days, and functional symptoms showed a similar trend, but emotional symptoms did not significantly decrease (Table 2). Withdrawal symptoms collected on test days did not correlate with outcome measures collected that day (all $P>0.1$ ), except for physical symptoms on functional magnetic resonance imaging day correlating with amygdala signal change $(r=0.436$, $P=0.042)$.

\section{Outcome measures}

Risk allele distribution. $\chi^{2}$ analyses assessing SERT allele distributions found no differences in risk allele loads between MA and control groups (Table 1).

Aggression questionnaire. Analysis of variance of $\mathrm{AQ}$ scores, with MA abuse status (MA or control) and genetic risk (low or high) as factors, showed significant effects of MA abuse $(F(1,67)=11.62, P=0.001)$ and genetic risk $(\mathrm{F}(1,67)=7.92, P=0.006)$, but no interaction $(\mathrm{F}(1,67)=$ $0.06, P=0.81$ ) (Figure 1a). As predicted, MA-dependent and high genetic risk participants reported greater aggression than their counterparts. These effects persisted when age, education and ethnicity were entered as additional covariates; entering sex as an additional factor (as allelic directionality can differ between sexes) showed no main effect of sex or sex $\times$ genetic risk interaction, while the effects of MA abuse and genetic risk remained significant. Performing the analysis of variance in a subsample matched for ethnicity (Caucasian only, as this comprised the largest ethnic subgroup: MA, $N=17$ (12 low risk); control, $N=22$ (10 low risk)) yielded identical results, suggesting that ethnic makeup of the sample did not bias outcome.

Amygdala ROI analysis. Percent signal change in the amygdala did not differ between neutral and emotional faces $(t(46)=0.89, P=0.38)$, and values were combined by calculating their average. Further, signal change correlated between left and right amygdala ROIs $(r=0.82, P<0.001)$, and values were combined by calculating a volume-weighted average. Analysis of variance of these values, with MA abuse status and genetic risk as factors, showed a significant effect of genetic risk $(F(1,41)=5.81, P=0.021)$, but no effect of $M A$ abuse $(F(1,41)=1.18, P=0.29)$ or interaction $(F(1,41)=$ $0.66, P=0.42$ ) (Figure 1b). Signal change in the amygdala was lower in high-risk than low-risk participants. This effect persisted when age, education and ethnicity were entered as additional covariates; entering sex as an additional factor showed no main effect of sex or sex $\times$ genetic risk interaction, while the effect of genetic risk remained significant.
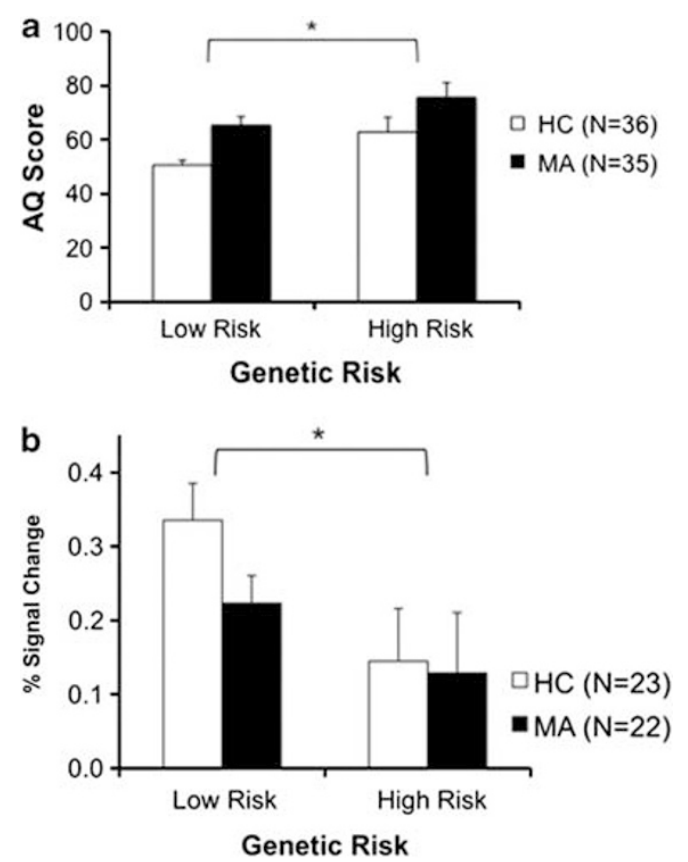

Figure 1 (a) Mean (s.e.m.) Aggression Questionnaire (AQ) scores of participants in the low genetic risk (MA, $N=22$; control, $N=19$ ) and high genetic risk (MA, $N=13$; control, $N=17$ ) groups. MA-dependent participants reported significantly higher aggression than control participants, and high genetic risk participants reported significantly higher aggression than low genetic risk participants. There was no MA abuse $\times$ genetic risk interaction. (b) Mean (s.e.m.) percent signal change in the amygdala during observation of faces for participants in the low genetic risk (MA, $N=13$; control, $N=12$ ) and high genetic risk (MA, $N=9$; control, $N=11$ ) groups. High-risk participants showed significantly less signal change in the amygdala than low-risk participants. There was no effect of MA abuse or interaction. ${ }^{*} P<0.05$. $\mathrm{HC}$, healthy control; MA, methamphetaminedependent.

Table 2 MA withdrawal measures

\begin{tabular}{|c|c|c|c|c|c|}
\hline & Day of intake & Day of $A Q$ & Test for difference from intake & Day of scan & Test for difference from intake \\
\hline Days abstinent (M, s.d.) & $1.09(1.54)$ & $6.92(1.91)$ & NA & $8.56(3.05)$ & NA \\
\hline $\begin{array}{l}\text { MAWQ score (M, s.d.) } \\
\text { Emotional (range 0-27) } \\
\text { Physical (range 0-21) } \\
\text { Functional (range 0-18) }\end{array}$ & $\begin{array}{l}3.45(3.90) \\
1.43(2.06) \\
3.33(3.14)\end{array}$ & $\begin{array}{l}2.65(3.24) \\
0.57(1.09) \\
2.41(2.32)\end{array}$ & $\begin{array}{c}t(36)=1.05 \\
t(36)=2.73^{\star} \\
t(36)=1.17\end{array}$ & $\begin{array}{l}3.10(3.40) \\
0.75(1.21) \\
2.45(2.30)\end{array}$ & $\begin{array}{c}t(28)<1 \\
t(28)=2.05^{\star} \\
t(28)=1.95(P<0.1)\end{array}$ \\
\hline MA craving (M, s.d.) & $50.9(28.7)$ & $28.3(29.4)$ & $t(34)=5.58^{*}$ & $30.6(30.3)$ & $t(32)=3.05^{\star}$ \\
\hline
\end{tabular}

Abbreviations: AQ, Aggression Questionnaire; MA, methamphetamine; MAWQ, Methamphetamine Withdrawal Questionnaire; NA, not applicable. ${ }^{\star} P<0.05$. 
A similar (but nonsignificant) effect was found in a subsample matched for ethnicity (Caucasian only: MA, $N=13$ (8 low risk); control, $N=12$ (5 low risk)). Amount of MA used (g per week) (Table 1) correlated inversely with signal change in the amygdala ( $r=-0.710, P<0.001$ ), and frequency of use (days per month) showed a similar trend $(r=-0.393, P=0.063)$.

Whole-brain analysis. To identify regions in which activation varied with SERT genotype, we queried voxels active during observation of faces (vs fixation) for a main effect of genetic risk (low risk vs high risk). Regions showing this effect included occipital cortex, fusiform and supramarginal gyri, and ventrolateral, dorsolateral and dorsomedial PFC (Figure $2 \mathrm{a}$ and Table 3). To identify regions in which activation differed by MA abuse status, we compared voxels active during observation of faces between MA and control participants. Regions showing this effect included occipital cortex and right ventrolateral and dorsolateral PFC (Figure $2 \mathrm{~b}$ and Table 3). A cluster in right ventrolateral PFC showed effects of both genetic risk and MA abuse (Table 3).

\section{Discussion}

Our investigation suggests that although SERT genotype influences aggression and brain function, this effect appears to be independent from that of MA. We found no evidence for higher SERT risk allele loads in the MA-dependent group, and no interaction between $M A$ abuse and genetic risk in predicting aggression ( $A Q$ scores). The imaging findings suggest that genotype and MA abuse act via distinct neural substrates, overlapping only in right ventrolateral PFC. However, it should be noted that the present sample was relatively small, and negative findings should be interpreted with caution.
Our finding of comparable SERT risk allele loads between MA-dependent and control groups in the present sample is consistent with a previous study, ${ }^{55}$ and is the first report of the relative distribution of STin2 alleles in these groups. The findings argue against the possibility that a disproportionate load of SERT risk alleles in MA-dependent populations drives observed differences in aggression and neurocircuitry. However, only three SERT polymorphisms were queried, and SERT is among many polymorphic genes influencing aggression, ${ }^{65}$ suggesting that other genetic loci may play a role. It is also possible that owing to differences in early environmental experiences, ${ }^{66}$ differential gene $\times$ environment interactions led to distinct outcomes despite similar SERT allele distributions. Given the relatively small sample size, the possibility that the analysis was not adequately powered to detect differences in genotype distribution cannot be excluded. Replication in a sufficiently large sample ( $n>7866$, given post-hoc power analyses with present effect sizes) would be necessary to conclusively interpret this negative finding.

The aggression self-report findings, showing effects of both MA abuse and genetic risk, are consistent with previous reports of heightened hostility and aggression in MA-abusing samples, ${ }^{2-8}$ as well as evidence for LPR short allele and STin2 12-repeat allele involvement in social-cognitive and emotional phenotypes associated with aggression. ${ }^{31-35}$ However, there was no interaction between these factors, suggesting that MA abuse and SERT genotype influence aggression via distinct mechanisms.

One such distinction may involve the amygdala, as its activation showed an effect of genetic risk, but not MA abuse. Our finding of SERT-related variation in amygdala activation is consistent with previous reports; ${ }^{42-44}$ however, the direction of the effect was unexpected. In previous studies, LPR shortallele carriers have exhibited amygdala hyperactivation,
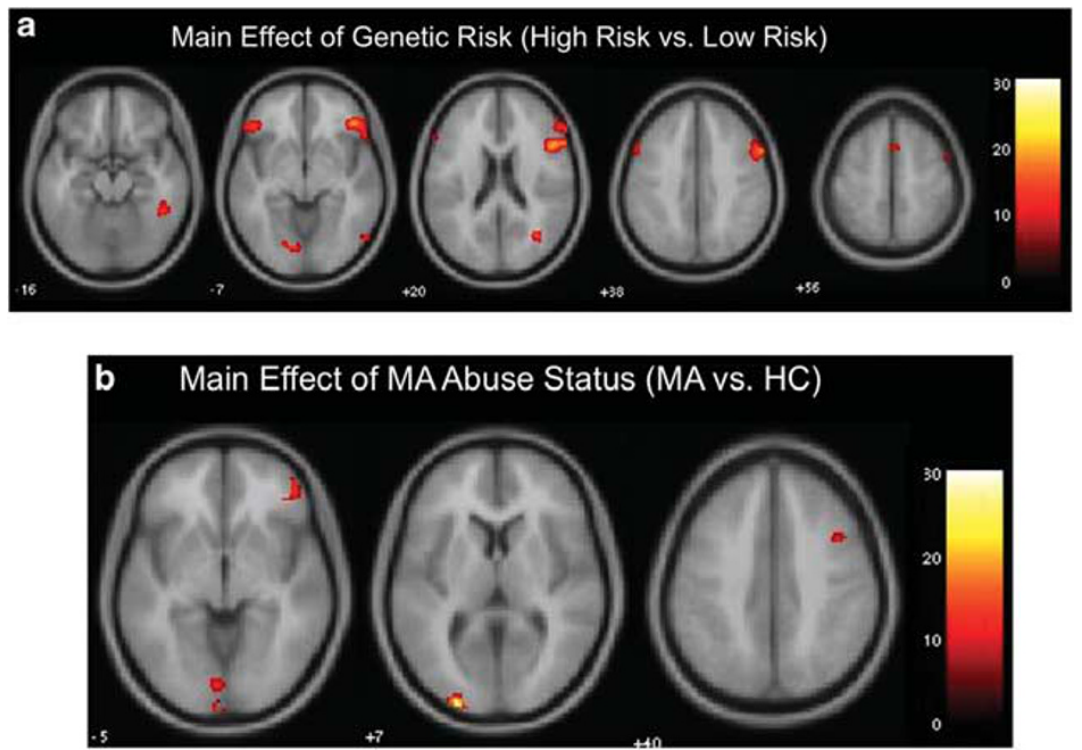

Figure 2 Statistical maps overlaid onto a standard structural template provided by SPM5. (a) Regions showing a main effect of genetic risk (low vs high) in activation associated with observation of faces. Regions included occipital cortex, fusiform and supramarginal gyri, and ventrolateral, dorsolateral and dorsomedial prefrontal cortex (see Table 3). (b) Regions showing a main effect of MA abuse status (MA vs HC) in activation associated with observation of faces. Regions included occipital cortex and right ventrolateral and dorsolateral prefrontal cortex (see Table 3). HC, healthy control; MA, methamphetamine-dependent; SPM, statistical parametric mapping. 
Table 3 SPM clusters for observation of faces (compared with fixation)

\begin{tabular}{|c|c|c|c|c|c|c|c|}
\hline \multirow[t]{2}{*}{ Contrast } & \multirow[t]{2}{*}{ Region } & \multirow[t]{2}{*}{$\begin{array}{l}\text { Direction } \\
\text { of effect }\end{array}$} & \multicolumn{3}{|c|}{$\begin{array}{l}\text { MNI coordinates of } \\
\text { peak voxel }(\mathrm{mm})\end{array}$} & \multirow[t]{2}{*}{ F-value } & \multirow[t]{2}{*}{$\begin{array}{l}\text { Cluster size } \\
\text { (voxels) }\end{array}$} \\
\hline & & & $\mathbf{x}$ & y & $\mathbf{z}$ & & \\
\hline \multicolumn{8}{|c|}{ Main effect of genetic risk (low risk vs high risk) } \\
\hline & \multirow[t]{2}{*}{$\begin{array}{l}\text { Right inferior frontal gyrus/ } \\
\text { orbitofrontal cortex }\end{array}$} & \multirow[t]{2}{*}{$\mathrm{LR}>\mathrm{HR}$} & 42 & 32 & 4 & 25.2 & \multirow[t]{2}{*}{2096} \\
\hline & & & $\begin{array}{l}50 \\
60\end{array}$ & $\begin{array}{l}16 \\
18\end{array}$ & $\begin{array}{l}22 \\
12\end{array}$ & $\begin{array}{l}21.7 \\
20.1\end{array}$ & \\
\hline & \multirow[t]{2}{*}{$\begin{array}{l}\text { Left inferior frontal gyrus/ } \\
\text { orbitofrontal cortex }\end{array}$} & \multirow[t]{2}{*}{$\mathrm{LR}>\mathrm{HR}$} & -60 & 18 & 30 & 19.3 & \multirow[t]{2}{*}{613} \\
\hline & & & $\begin{array}{l}-44 \\
-46\end{array}$ & $\begin{array}{l}22 \\
32\end{array}$ & $\begin{array}{r}4 \\
-8\end{array}$ & $\begin{array}{l}17.4 \\
15.0\end{array}$ & \\
\hline & $\begin{array}{l}\text { Right lateral occipital cortex } \\
\text { Right lateral occipital cortex }\end{array}$ & $\begin{array}{l}\mathrm{LR}>\mathrm{HR} \\
\mathrm{LR}>\mathrm{HR}\end{array}$ & $\begin{array}{l}58 \\
34\end{array}$ & $\begin{array}{l}-72 \\
-66\end{array}$ & $\begin{array}{r}0 \\
18\end{array}$ & $\begin{array}{l}18.7 \\
17.2\end{array}$ & $\begin{array}{r}37 \\
104\end{array}$ \\
\hline & Left lingual gyrus & $H R>L R$ & -10 & -80 & -6 & 14.7 & 61 \\
\hline & Right fusiform gyrus ${ }^{a}$ & $\mathrm{LR}>\mathrm{HR}$ & 44 & -44 & -18 & 14.1 & 175 \\
\hline & Right supramarginal gyrus ${ }^{a}$ & $\mathrm{LR}>\mathrm{HR}$ & 52 & -40 & 10 & 12.8 & 140 \\
\hline & Superior frontal/paracingulate gyrus & $\mathrm{LR}>\mathrm{HR}$ & 2 & 12 & 56 & 10.2 & 34 \\
\hline \multirow{7}{*}{$\begin{array}{l}\text { Main effect of MA abuse status } \\
\text { (MA-dependent vs control) }\end{array}$} & Left occipital cortex & $\mathrm{HC}>\mathrm{MA}$ & -26 & -98 & 8 & 28.0 & 135 \\
\hline & Left occipital cortex & $\mathrm{HC}>\mathrm{MA}$ & -2 & -102 & -8 & 17.2 & 34 \\
\hline & Left lingual gyrus & $\mathrm{HC}>\mathrm{MA}$ & -2 & -84 & -2 & 13.6 & 78 \\
\hline & $\begin{array}{l}\text { Right inferior frontal gyrus/ } \\
\text { orbitofrontal cortex }\end{array}$ & $\mathrm{HC}>\mathrm{MA}$ & $4 \overline{8}$ & 46 & -2 & 12.9 & 125 \\
\hline & Right middle frontal gyrus ${ }^{a}$ & \multirow{4}{*}{$\begin{array}{l}\mathrm{HC}>\mathrm{MA} \\
\mathrm{HC}>\mathrm{MA} \\
\mathrm{HC}>\mathrm{MA}\end{array}$} & \multirow{4}{*}{$\begin{array}{r}38 \\
-32 \\
36 \\
44\end{array}$} & \multirow{4}{*}{$\begin{array}{r}10 \\
-14 \\
6 \\
40\end{array}$} & \multirow{4}{*}{$\begin{array}{r}44 \\
66 \\
58 \\
-6\end{array}$} & 12.4 & \multirow{4}{*}{$\begin{array}{l}89 \\
38 \\
37 \\
33\end{array}$} \\
\hline & Right precentral gyrus & & & & & 12.0 & \\
\hline & Left precentral gyrus & & & & & 10.8 & \\
\hline Overlap between effects & $\begin{array}{l}\text { Right inferior frontal gyrus/ } \\
\text { orbitofrontal cortex }\end{array}$ & & & & & 12.7 & \\
\hline
\end{tabular}

Abbreviations: HC, healthy control group; HR, high-risk group; LR, low-risk group; MA, methamphetamine-dependent group; MNI, Montreal Neurological Institute; SPM, statistical parametric mapping.

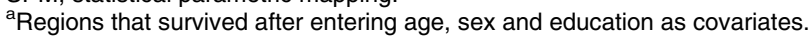

whereas in the present sample, signal change was lower in this group. It is possible that the finding reflects tonic hyperactivity of the amygdala in the high-risk group, creating a ceiling effect, while individuals in the low-risk group can accommodate a larger change in activation. Several lines of evidence support this view, including a 'tonic model', ${ }^{67}$ suggesting that carriers of the LPR short allele have high amygdala activity at rest and during neutral and undefined conditions. ${ }^{68-70}$ In addition, amygdala activation in the present MA-dependent sample correlated inversely with MA use measures (amount and frequency), so that that the lowest signal change occurred in those participants who used MA most heavily. Heavy MA use has been associated with high glucose metabolism in the amygdala, ${ }^{21}$ suggesting that in the present sample, the lowest activation reflected the highest glucose metabolism (tonic activity). The direction of the effect may therefore reflect the relative nature of functional magnetic resonance imaging, rather than an actual reversal of the effect.

Our finding that amygdala activation did not differ between MA-dependent and healthy participants suggests that heightened MA-related aggression may occur via mechanisms independent of the amygdala (for example, higher cognitive and executive processes, life and social experiences or personality traits). Again, we cannot exclude the possibility that our sample size did not permit detection of differences. Replication in a sufficiently large sample $(n>275$, given post-hoc power analyses with present effect sizes) would be necessary to conclusively interpret this negative finding.
Finally, both MA abuse and genetic risk modulated activation in cortical regions linked to emotion processing, but the regions showed little overlap. Genetic risk influenced the core system for visual analysis of faces, ${ }^{71}$ and PFC regions involved in recognition and interpretation of facial affect, calculation of stimulus contingencies and regulation of emotional responses, ${ }^{11,72}$ consistent with the idea that SERTrelated aggression is linked to social-cognitive neurocircuitry. Effects of MA abuse were less manifest, revealing only small activation differences in PFC and occipital cortex. While also part of emotion processing circuitry, the roles of these regions are less clear. Among the regions identified, the only one that showed overlap between genotype and MA effects was the right ventrolateral $\mathrm{PFC}$, a region implicated in social cognition and inhibitory control. ${ }^{13,14}$ The overlap suggests that this region modulates aggression regardless of sources of variation (genotype or MA abuse), suggesting it may have utility as a biomarker for risk or intervention. Taken together, the data suggest that the effects of MA abuse add to-but mostly do not interact with-genetic risk in modulating aggression and associated neurocircuitry.

Several limitations of the study should be noted. First, statistical power was limited owing to sample size. We maximized power by combining groups, using a small number of outcome measures and including an ROI approach in functional magnetic resonance imaging analyses. Second, not all withdrawal symptoms resolved by the time of testing, possibly confounding results; however, symptoms 
and outcome measures were not correlated, suggesting that outcomes were independent of withdrawal. In addition, data were obtained at only one point following a brief abstinence period; differences in brain activation may vary with time. Third, our method for combining genotypes was based on one prior study in a prison population, ${ }^{51}$ and generalization to other populations is uncertain; however, our results using both combined and individual variants (see Supplementary Materials) support using this strategy more broadly. Finally, comparable amygdala activation between negative and neutral faces calls into question the psychological significance of the probe task. However, although broad, the measured psychological operation ('detection of socially salient environmental cues') appears highly relevant to aggression, and as such, meaningful to investigate. Potential reasons for comparable amygdala activation between stimulus types are small sample size/low statistical power, attribution of negative valence to neutral faces ${ }^{73,74}$ or general role of the amygdala in detecting socially relevant stimuli rather than merely threat. ${ }^{75}$

In summary, this study adds to our understanding of genotype- and MA-related modulation of aggression and social-cognitive neurocircuitry, suggesting that differences associated with MA abuse occur independently of, and in addition to, the predisposing influence of SERT genotype; it is therefore important to recognize that in a certain proportion of MA-dependent individuals, mere abstinence from MA or attention to MA-use effects will not be sufficient in decreasing propensity for aggression and violence (and, thereby, minimizing risk for stress-induced relapse). At the same time, the findings point to right ventrolateral PFC as a potential biomarker for both MA- and genotype-related aggression, suggesting that modulation of its function may allay this behavior regardless of its source. In light of these findings, continued investigation of socio-emotional function and its neurobiological underpinnings will be critical in addressing problematic behaviors and developing appropriate strategies for intervention.

\section{Conflict of interest}

Dr McCracken reports receiving research grants from Seaside Therapeutics and Bristol Myers Squibb, and has served as a consultant to Roche, Novartis, BioMarin and PharmaNet. The remaining authors declare no conflict of interest.

Acknowledgements. This research was supported by $\mathrm{NIH}$ research Grants R01 DA020726, R01 DA015179, P20 DA022539 (EDL); F31 DA025422 (DEP); T90 DA022768, T32 DA024635 (EDL), T32 MH073517 (JTM); M01 RR00865 (UCLA GCRC); and endowments from the Thomas P. and Katherine K. Pike Chair in Addiction Studies and the Marjorie M. Greene Family Trust (EDL) We also thank Drs Catherine Sugar and Gerhard Helleman for assistance with statistical calculations.

1. Boles SM, Miotto K. Substance abuse and violence: a review of the literature. Aggress Violent Behav 2003; 8: 155-174.

2. Cohen JB, Dickow A, Horner K, Zweben JE, Balabis J, Vandersloot D et al. Abuse and violence history of men and women in treatment for methamphetamine dependence. Am J Addict 2003; 12: 377-385.

3. Baskin-Sommers A, Sommers I. Methamphetamine use and violence among young adults. J Crim Just 2006; 34: 661-674.

4. Cartier J, Farabee D, Prendergast ML. Methamphetamine use, self-reported violent crime, and recidivism among offenders in California who abuse substances. J Interpers Violence 2006; 21: 435-445.
5. Sekine Y, Ouchi Y, Takei N, Yoshikawa E, Nakamura K, Futatsubashi M et al. Brain serotonin transporter density and aggression in abstinent methamphetamine abusers. Arch Gen Psychiatry 2006; 63: 90-100.

6. Payer DE, Lieberman MD, Monterosso JR, Xu J, Fong TW, London ED. Differences in cortical activity between methamphetamine-dependent and healthy individuals performing a facial affect matching task. Drug Alcohol Depend 2008; 93: 93-102.

7. Hamilton A, Goeders N. Violence perpetrated by women who use methamphetamine. J Substance Use 2010; 15: 313-329.

8. Payer DE, Lieberman MD, London ED. Neural correlates of affect processing and aggression in methamphetamine dependence. Arch Gen Psychiatry 2011; 68: 271-282.

9. Coccaro EF. Neurotransmitter correlates of impulsive aggression in humans. Ann $N Y$ Acad Sci 1996; 794: 82-89.

10. Nelson RJ, Trainor BC. Neural mechanisms of aggression. Nat Rev Neurosci 2007; 8: 536-546.

11. Davidson RJ, Putnam KM, Larson CL. Dysfunction in the neural circuitry of emotion regulation-a possible prelude to violence. Science 2000; 289: 591-594.

12. Siever LJ. Neurobiology of aggression and violence. Am J Psychiatry 2008; 165: 429-442.

13. Baicy K, London ED. Corticolimbic dysregulation and chronic methamphetamine abuse. Addiction 2007; 102(Suppl 1): 5-15.

14. Payer $\mathrm{D}$, London $E D$. Methamphetamine and the brain: findings from brain imaging studies. In: Roll JM, Rawson R, Ling W, Shoptaw S (eds). Methamphetamine Addiction: From Basic Science to Treatment. Guildford Press: New York, 2009, pp 61-91.

15. Kish SJ, Fitzmaurice PS, Boileau I, Schmunk GA, Ang LC, Furukawa Y et al. Brain serotonin transporter in human methamphetamine users. Psychopharmacology (Berl) 2009; 202: 649-661.

16. Homer BD, Solomon TM, Moeller RW, Mascia A, DeRaleau L, Halkitis PN. Methamphetamine abuse and impairment of social functioning: a review of the underlying neurophysiological causes and behavioral implications. Psychol Bull 2008; 134: 301-310.

17. Henry JD, Mazur M, Rendell PG. Social-cognitive difficulties in former users of methamphetamine. Br J Clin Psychol 2009; 48: 323-327.

18. Kim YT, Kwon DH, Chang Y. Impairments of facial emotion recognition and theory of mind in methamphetamine abusers. Psychiatry Res 2010; Jul: 17.

19. Goldstein RZ, Craig AD, Bechara A, Garavan H, Childress AR, Paulus MP et al. The neurocircuitry of impaired insight in drug addiction. Trends Cogn Sci 2009; 13: 372-380.

20. Goldstein RZ, Volkow ND, Chang L, Wang GJ, Fowler JS, Depue RA et al. The orbitofrontal cortex in methamphetamine addiction: involvement in fear. NeuroReport 2002; 13: 2253-2257.

21. London ED, Simon SL, Berman SM, Mandelkern MA, Lichtman AM, Bramen J et al. Mood disturbances and regional cerebral metabolic abnormalities in recently abstinent methamphetamine abusers. Arch Gen Psychiatry 2004; 61: 73-84.

22. Gonzales R, Mooney L, Rawson RA. The methamphetamine problem in the United States. Annu Rev Public Health 2010; 31: 385-398.

23. Li CS, Sinha R. Inhibitory control and emotional stress regulation: neuroimaging evidence for frontal-limbic dysfunction in psycho-stimulant addiction. Neurosci Biobehav Rev (Research Support, NIH, Extramural Research Support, Non-US Gov't Review) 2008; 32: 581-597.

24. Yamamoto BK, Moszczynska A, Gudelsky GA. Amphetamine toxicities: classical and emerging mechanisms. Ann N Y Acad Sci 2010; 1187: 101-121.

25. Krasnova IN, Cadet JL. Methamphetamine toxicity and messengers of death. Brain Res Rev 2009; 60: 379-407.

26. Anguelova M, Benkelfat $C$, Turecki $G$. A systematic review of association studies investigating genes coding for serotonin receptors and the serotonin transporter: I. Affective disorders. Mol Psychiatry 2003; 8: 574-591.

27. Serretti A, Calati R, Mandelli L, De Ronchi D. Serotonin transporter gene variants and behavior: a comprehensive review. Curr Drug Targets 2006; 7: 1659-1669.

28. Wrase J, Reimold M, Puls I, Kienast T, Heinz A. Serotonergic dysfunction: brain imaging and behavioral correlates. Cogn Affect Behav Neurosci 2006; 6: 53-61.

29. Wendland JR, Martin BJ, Kruse MR, Lesch KP, Murphy DL. Simultaneous genotyping of four functional loci of human SLC6A4, with a reappraisal of 5-HTTLPR and rs25531. Mol Psychiatry 2006; 11: 224-226.

30. Heils A, Teufel A, Petri S, Stober G, Riederer P, Bengel D et al. Allelic variation of human serotonin transporter gene expression. J Neurochem 1996; 66: 2621-2624.

31. Haberstick BC, Smolen A, Hewitt JK. Family-based association test of the 5HTTLPR and aggressive behavior in a general population sample of children. Biol Psychiatry 2006; 59: 836-843.

32. Gerra G, Garofano L, Castaldini L, Rovetto F, Zaimovic A, Moi G et al. Serotonin transporter promoter polymorphism genotype is associated with temperament, personality traits and illegal drugs use among adolescents. J Neural Transm 2005; 112: 1397-1410.

33. Lesch KP, Merschdorf U. Impulsivity, aggression, and serotonin: a molecular psychobiological perspective. Behav Sci Law 2000; 18: 581-604.

34. Beitchman JH, Baldassarra L, Mik H, De Luca V, King N, Bender D et al. Serotonin transporter polymorphisms and persistent, pervasive childhood aggression. $A m \mathrm{~J}$ Psychiatry 2006; 163: 1103-1105.

35. Sakai JT, Young SE, Stallings MC, Timberlake D, Smolen A, Stetler GL et al. Case-control and within-family tests for an association between conduct disorder and $5 \mathrm{HTTLPR}$. Am J Med Genet (Neuropsychiatr Genet) 2006; 141B: 825-832. 
36. Lotrich FE, Pollock BG. Meta-analysis of serotonin transporter polymorphisms and affective disorders. Psychiatr Genet 2004; 14: 121-129.

37. Sen S, Burmeister M, Ghosh D. Meta-analysis of the association between a serotonin transporter promoter polymorphism (5-HTTLPR) and anxiety-related personality traits. Am J Med Genet B 2004; 127B: 85-89.

38. Schinka JA, Busch RM, Robichaux-Keene N. A meta-analysis of the association between the serotonin transporter gene polymorphism (5-HTTLPR) and trait anxiety. Mol Psychiatry 2004; 9: 197-202.

39. Way BM, Lieberman MD. Is there a genetic contribution to cultural differences? Collectivism, individualism and genetic markers of social sensitivity. Soc Cogn Affect Neurosci 2010; 5: 203-211.

40. Izquierdo A, Newman TK, Higley JD, Murray EA. Genetic modulation of cognitive flexibility and socioemotional behavior in rhesus monkeys. Proc Natl Acad Sci USA 2007; 104: 14128-14133.

41. Chiao JY, Blizinsky KD. Culture-gene coevolution of individualism-collectivism and the serotonin transporter gene. Proc Biol Sci 2010; 277: 529-537.

42. Pacheco J, Beevers CG, Benavides C, McGeary J, Stice E, Schnyer DM. Frontal-limbic white matter pathway associations with the serotonin transporter gene promoter region (5HTTLPR) polymorphism. J Neurosci 2009; 29: 6229-6233.

43. Brown SM, Hariri AR. Neuroimaging studies of serotonin gene polymorphisms: exploring the interplay of genes, brain, and behavior. Cogn Affect Behav Neurosci 2006; 6: 44-52.

44. Frodl T, Koutsouleris N, Bottlender R, Born C, Jager M, Morgenthaler M et al. Reduced gray matter brain volumes are associated with variants of the serotonin transporter gene in major depression. Mol Psychiatry 2008; 13: 1093-1101.

45. Beitchman JH, Davidge KM, Kennedy JL, Atkinson L, Lee V, Shapiro S et al. The serotonin transporter gene in aggressive children with and without ADHD and nonaggressive matched controls. Ann N Y Acad Sci 2003; 1008: 248-251.

46. Davidge KM, Atkinson L, Douglas L, Lee V, Shapiro S, Kennedy JL et al. Association of the serotonin transporter and $5 \mathrm{HT} 1$ Dbeta receptor genes with extreme, persistent and pervasive aggressive behaviour in children. Psychiatr Genet 2004; 14: 143-146.

47. Collier DA, Arranz MJ, Sham P, Battersby S, Vallada H, Gill $P$ et al. The serotonin transporter is a potential susceptibility factor for bipolar affective disorder. NeuroReport 1996; 7: 1675-1679.

48. Ohara K, Suzuki Y, Ochiai M, Tsukamoto T, Tani K. A variable-number-tandem-repeat of the serotonin transporter gene and anxiety disorders. Prog Neuropsychopharmacol Biol Psychiatry 1999; 23: 55-65.

49. Baca-Garcia E, Vaquero-Lorenzo C, Diaz-Hernandez M, Rodriguez-Salgado B, DolengevichSegal $\mathrm{H}$, Arrojo-Romero $\mathrm{M}$ et al. Association between obsessive-compulsive disorder and a variable number of tandem repeats polymorphism in intron 2 of the serotonin transporter gene. Prog Neuro-Psychopharmacol Biol Psychiatry 2007; 31: 416-420.

50. Oades RD, Lasky-Su J, Christiansen H, Faraone SV, Sonuga-Barke EJ, Banaschewski T et al. The influence of serotonin- and other genes on impulsive behavioral aggression and cognitive impulsivity in children with attention-deficit/hyperactivity disorder (ADHD): Findings from a family-based association test (FBAT) analysis. Behav Brain Funct 2008; 4: 48

51. Aluja A, Garcia LF, Blanch A, De Lorenzo D, Fibla J. Impulsive-disinhibited personality and serotonin transporter gene polymorphisms: association study in an inmate's sample. $J$ Psychiatr Res 2009; 43: 906-914.

52. Ali FR, Vasiliou SA, Haddley K, Paredes UM, Roberts JC, Miyajima F et al. Combinatorial interaction between two human serotonin transporter gene variable number tandem repeats and their regulation by CTCF. J Neurochem 2010; 112: 296-306.

53. Hranilovic D, Stefulj J, Schwab S, Borrmann-Hassenbach M, Albus M, Jernej B et al. Serotonin transporter promoter and intron 2 polymorphisms: relationship between allelic variants and gene expression. Biol Psychiatry 2004; 55: 1090-1094.

54. Ezaki N, Nakamura K, Sekine Y, Thanseem I, Anitha A, Iwata $Y$ et al. Short allele of 5HTTLPR as a risk factor for the development of psychosis in Japanese methamphetamine abusers. Ann N Y Acad Sci 2008; 1139: 49-56.

55. Hong CJ, Cheng CY, Shu LR, Yang CY, Tsai SJ. Association study of the dopamine and serotonin transporter genetic polymorphisms and methamphetamine abuse in Chinese males. J Neural Transm 2003; 110: 345-351.

56. First MB, Spitzer RL, Gibbon M, Williams JBW. The Structured Clinical Interview for DSMIV Axis I Disorders (SCID-IP). American Psychiatric Press: Washington, DC, 1995.

57. Buss AH, Perry M. The aggression questionnaire. J Pers Soc Psychol 1992; 63: 452-459.

58. Sergerie $\mathrm{K}$, Chochol $\mathrm{C}$, Armony JL. The role of the amygdala in emotional processing: a quantitative meta-analysis of functional neuroimaging studies. Neurosci Biobehav Rev 2008; 32: 811-830.

59. Tottenham N, Tanaka J, Leon AC, McCarry T, Nurse M, Hare TA et al. The NimStim set of facial expressions: Judgments from untrained research participants. Psychiatry Res 2009; 168: 242-249.

60. Zorick T, Nestor L, Miotto K, Sugar C, Hellemann G, Scanlon G et al. Withdrawal symptoms in abstinent methamphetamine-dependent subjects. Addiction 2010; 105 1809-1818.

61. Lovejoy EA, Scott AC, Fiskerstrand CE, Bubb VJ, Quinn JP. The serotonin transporter intronic VNTR enhancer correlated with a predisposition to affective disorders has distinct regulatory elements within the domain based on the primary DNA sequence of the repeat unit. Eur J Neurosci (Research Support, Non-US Gov't) 2003; 17: 417-420.

62. Patenaude B, Smith S, Kennedy D, Jenkinson M. FIRST_FMRIB's Integrated Registration and Segmentation Tool. Annual Meeting of the Organization for Human Brain Mapping 2007; Chicago, IL.

63. Brett M, Anton JL, Valabregue R, Poline JB. Region of interest analysis using an SPM toolbox. Neurolmage 2002; 16: 1140-1141.

64. Lieberman MD, Cunningham WA. Type I and Type II error concerns in fMRI research: rebalancing the scale. Soc Cogn Affect Neurosci 2009; 4: 423-428.

65. Craig IW, Halton KE. Genetics of human aggressive behaviour. Hum Genet 2009; 126 101-113.

66. Schafer I, Langeland W, Hissbach J, Luedecke C, Ohlmeier MD, Chodzinski C; et al. Childhood trauma and dissociation in patients with alcohol dependence, drug dependence, or both-a multi-center study. Drug Alcohol Depend 2010; 109: 84-89.

67. Canli T, Lesch KP. Long story short: the serotonin transporter in emotion regulation and social cognition. Nat Neurosci 2007; 10: 1103-1109.

68. Canli T, Qiu M, Omura K, Congdon E, Haas BW, Amin Z et al. Neural correlates of epigenesis. Proc Natl Acad Sci USA 2006; 103: 16033-16038.

69. Rao H, Gillihan SJ, Wang J, Korczykowski M, Sankoorikal GM, Kaercher KA et al. Genetic variation in serotonin transporter alters resting brain function in healthy individuals. Biol Psychiatry 2007; 62: 600-606.

70. Heinz A, Smolka MN, Braus DF, Wrase J, Beck A, Flor $\mathrm{H}$ et al. Serotonin transporter genotype (5-HTTLPR): effects of neutral and undefined conditions on amygdala activation. Biol Psychiatry 2007; 61: 1011-1014

71. Haxby JV, Hoffman EA, Gobbini MI. The distributed human neural system for face perception. Trends Cogn Sci 2000; 4: 223-233.

72. Adolphs R. Recognizing emotion from facial expressions: psychological and neurological mechanisms. Behav Cogn Neurosci Rev 2002; 1: 21-62.

73. Lee E, Kang Jl, Park IH, Kim JJ, An SK. Is a neutral face really evaluated as being emotionally neutral? Psychiatry Res (Research Support, Non-US Gov't Validation Studies) 2008; 157: 77-85.

74. Pinkham AE, Brensinger C, Kohler C, Gur RE, Gur RC. Actively paranoid patients with schizophrenia over attribute anger to neutral faces. Schizophr Res (Research Support, NIH, Extramural) 2011; 125: 174-178.

75. Kleinhans NM, Johnson LC, Mahurin R, Richards T, Stegbauer KC, Greenson J et al. Increased amygdala activation to neutral faces is associated with better face memory performance. NeuroReport (Research Support, NIH, Extramural) 2007; 18: 987-991.

\section{(c)}

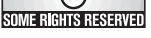
licensed under the Creative Commons Attribution-Noncommercial-No Derivative Works 3.0 Unported License. To view a copy of this license, visit http://creativecommons.org/licenses/by-nc-nd/3.0/

\section{Supplementary Information accompanies the paper on the Translational Psychiatry website (http://www.nature.com/tp)}

